\title{
Transfer of persistence in the domestic chick: Effects of imprinting experiences on later instrumental responses*
}

\author{
DANE RUSSO $\dagger$ \\ University of Texas, Austin, Texas 78712
}

\begin{abstract}
To test the effects of obstructed and unobstructed imprinting approach on subsequent instrumental responding, four groups of domestic chicks, in two separate replications, received imprinting or control treatment during the first week of life and later acquired a food-motivated running response in a runway for continuous reward. Runway acquisition results revealed no significant differences between imprinting (IM), imprinting/shock (IS), shock control (SK), and handling control (CN) Ss. However, significantly different patterns of persistence across groups and replications were evident during runway extinction. Results are explained in terms of a counterconditioning notion of response persistence.
\end{abstract}

The experimental and theoretical investigation of a dimension of behavior termed response persistence has gradually changed from a specific interest in the increased resistance to extinction that results from partial reinforcement schedules (the PRE) to a concern with more general determinants. The search for these more general determinants has led to a number of experiments testing not only the effects on subsequent persistence of interrupting ongoing behavior with a variety of disruptive stimuli, but also the degree to which these effects may transfer from one situation and one response system to another. It is becoming apparent that PRE treatments represent but one subset of a more general set of operations affecting persistence, even when persistence is ultimately evaluated in terms of resistance to extinction.

That response persistence can result from the introduction of disruptive stimuli other than nonreward has been well documented. The use of delay of reward (Donin, Surridge, \& Amsel, 1967), of shock (Brown \& Wagner, 1964; Wong, 1971) to disrupt runway approach, and of loud tones (Amsel, Glazer, Lakey, McCuller, \& Wong, 1973) to disrupt barpressing has been demonstrated to make these responses more resistant to extinction.

At least one test of the development of general persistence during early critical periods of life has been conducted. Amsel, Wong, and Scull (1971) found that chicks which had made approach responses to an imprinting stimulus, with or without shock obstruction,

*This report is based upon a portion of a dissertation submitted to the University of Texas in partial fulfillment of the requirements for the $\mathrm{PhD}$ degree. The author wishes to thank his Thesis Chairman, Abram Amsel, for advice and support during the und ertaking of this research. This research was supported by Grant GB-14990X from the National Science Foundation granted to Abram Amsel. Dr. Amsel sponsors this article and takes full editorial responsibility for its contents.

$+R$ equests for reprints should be sent to Dane Ru'sso, who is now at the Department of Psychology, University of South Carolina, Spartanburg, South Carolina 29303. were more persistent during the extinction of an instrumental food-motivated runway response.

The following experiment provides a further test of the notion that general persistence may result from counterconditioning processes in early life. The experiment is a partial replication of the Amsel et al (1971) experiment and represents an attempt to establish the strength and replicability of the effects reported in that experiment. The main purpose of the experiment was to determine if imprinting, with and without shock obstruction, increases the resistance to extinction of a subsequently trained, continuously food-rewarded running response.

\section{METHOD}

\section{Subjects}

The Ss were 34 Cornish $\mathrm{x}$ White Rock chicks hatched in the laboratory. All Ss were housed in individual brooder compartments when they were 4-12 h old. Brooder temperature was kept at $94^{\circ} \mathrm{F}$ during the first 2 weeks and $85^{\circ} \mathrm{F}$ throughout the remaind er of the experiment.

\section{Apparatus}

With the exception of a few minor modifications, all runway equipment employed in the present study was the same as that used in the Amsel et al (1971) experiment. The imprinting apparatus was a $3 \times 1 \times 1 \mathrm{ft}$ wooden alley painted flat black with an open top. A shock grid extending the length and width of the alley served as the floor. Three photocells connected to timers provided time measures over three $1-\mathrm{ft}$ segments. The visuálauditory stimulus was one of the interior end walls of the alley. The visual stimulus was a light flickering at a rate of $.5 \mathrm{sec}$ on and $.5 \mathrm{sec}$ off through a diamond pattern of four holes of 3/4-in diam, $4 \mathrm{in}$. apart, illuminated at $68 \mathrm{fc}$. The auditory stimulus, a $200-\mathrm{Hz}$ tone, was synchronous with the filcker and was emitted at the same end of the alley as the light stimulus by a small PM speaker. The intensity of the auditory stimulus was measured to be $85-90 \mathrm{~dB}$ at 6 in. from the source, against a background noice of $70 \mathrm{~dB}$ as measured on the $\mathrm{C}$ scale of a sound pressure level meter.

The entire imprinting alley was placed in a sound-treated box. A clear Plexiglas window on the top of the box permitted observation of the chick's behavior. The only illumination, other 


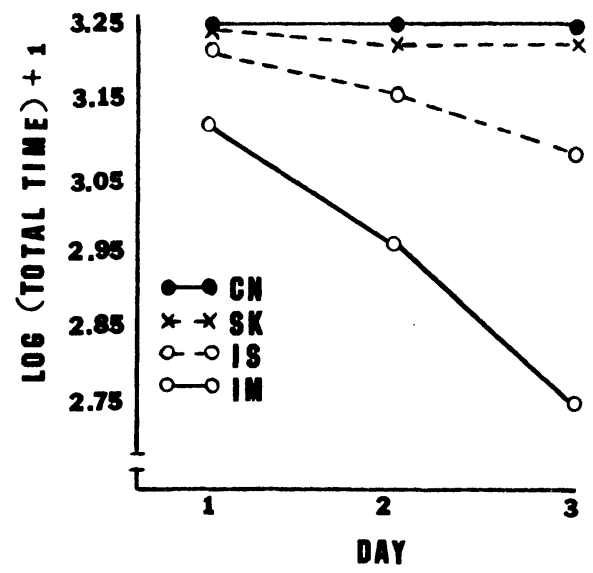

Fig. 1. Group mean log (total imprinting time) +1 scores for the 3 imprinting days.

than the flicker, was the ind irect lighting provided by an exposed 25 -W light bulb in the experimental room.

The chick runway, made of plywood, was 45 in. long, 6 in. wide, and the height was adjustable to accommodate the growing chick. The runway was painted white and was covered with milk-covered Plexiglas. The floor was $1 / 4$-in. hardware cloth mesh. Two guillotine doors were used to separate a 6-in.-long startbox and a 1-ft-long goal compartment. Three photocells and one microswitch, connected to timers, provided time measures over three $1-\mathrm{ft}$ segments. The raising of the startdoor activated the first clock, while the breaking of the last photobeam stopped the third clock. A $2-1 / 2 \times 1 \times 1$ in. food cup, 3 in. from the last photobeam, was hidden behind a metal end plate which had a $2 \times 2$ in. aperture to permit access to food.

\section{Design}

Imprinting and shock were combined factorially, resulting in four treatment conditions: imprinting/shock (IS), imprinting/no shock (IM), no imprinting/shock (SK), no imprinting/no shock (CN). The study was conducted in a series of two replications, with four chicks randomly assigned to each group in Replication 1 and five to each group in Replication 2.

\section{Procedure}

The Ss were 12-20 h old when first exposed to the imprinting stimulus. The imprinting phase lasted for 3 days, with four trials per day, 5 min per trial. Running order of the Ss was according to a predetermined random sequence, with the only restriction being that an IS chick always preceded its yoked SK mate.

Imprinting procedures were conducted in a darkened constant-temperature room kept at $80^{\circ} \mathrm{F}$. As soons as $\mathrm{S}$ was placed at the far end of the imprinting alley, the imprinting stimulus was switched on at the other end. The stimulus was terminated before $\mathrm{S}$ was removed. IS chicks received the same treatment except that 6 in. away from the imprinting stimulus, a $6 \times 12$ in. segment of the floor was electrified. Shock intensity was set at $1 \mathrm{~mA}$ on Day 1 , at $2 \mathrm{~mA}$ on Day 2 , and at $3 \mathrm{~mA}$ on Day 3. Each SK chick was yoked to an IS chick so that it received the same duration of the same shock intensity throughout imprinting. $\mathrm{CN}$ chicks were simply placed in the alley and not exposed to the imprinting stimulus.

Throughout the experiment, the following food deprivation schedule was maintained: Day 1-7, ad lib; Day 8, $4 \mathrm{~h}$ access to food; Day 9 until the end of the experiment, 20 min access. All Ss were fed about $15 \mathrm{~min}$ after the last $\mathrm{S}$ had completed its last daily trial.

Runway training began with 4 days of pretraining, two trials per day: Day 9, goalbox feeding; Days 10-12, shaping. Goalbox feeding consisted of placing each $\mathrm{S}$ in the goalbox and allowing $30 \mathrm{sec}$ of feeding during a maximum period of $5 \mathrm{~min}$. On Day 10 Ss were placed $1 \mathrm{ft}$ from goal. On Day 11 Ss were placed $2 \mathrm{ft}$ from the goal, and on Day 12 Ss were placed in the startbox. Ss were allowed $30 \mathrm{sec}$ of goalbox feeding during shaping.

Starting on Day 13, Ss received 40 acquisition and 40 extinction trials, 2 trials per day on Days 13 and 14 and 4 trials per day thereafter. Reinforcement consisted of $20 \mathrm{sec}$ access to Starter Krums. The minimum ITI was $10 \mathrm{~min}$. A maximum of $60 \mathrm{sec}$ was allowed for the crossing of each $1-\mathrm{ft}$ runway segment. If a chick failed to break the photobeam within this time, it was placed in the goalbox and all subsequent scores were recorded as $60 \mathrm{sec}$.

\section{RESULTS AND DISCUSSION}

\section{Imprinting}

Start, run, goal, and total times were each converted to $\log$ (time) +1 , and analyses of variance were done on each measure. In none of the analyses was the main effect of replication nor any of the interactions involving the replication and group factors significant. Since the start, run, goal, and total mesures showed essentially the same pattern, only the results from the total measure are presented. Figure 1 shows the group $\log$ (total time) +1 data for the 3 imprinting days.

The log (total time) + 1 means were $2.89,3.15,3.24$, and 3.25 for Groups IM, IS, K, and CN, respectively. Analysis of variance tests on the log total time scores revealed significant main effects of day $(F=10.22$, $\mathrm{df}=2 / 56, \mathrm{p}<.01)$ and of groups $(\mathrm{F}=7.80, \mathrm{df}=3 / 28$, $\mathrm{p}<.01)$. Improvement across and within days for IM and IS groups led to the following significant interactions: Day by Group $(\mathrm{F}=5.00, \mathrm{df}=6 / 56$, $\mathrm{p}<.01)$ and Day by Trial by Group $(\mathrm{F}=1.75$, $\mathrm{df}=18 / 168, \mathrm{p}<.05)$.

\section{Runway Training}

Since all measures of runway acquisition and extinction showed essentially the same pattern, only the results of the analysis of variance tests on total speed are presented except where noted. Figure 2 shoes the group total speed data for both acquisition and extinction.

In acquisition, a significant day effect $(F=133$, $\mathrm{df}=9 / 252, \mathrm{p}<.0001)$ indicated that all groups acquired the running response. A significant replication by day effect $(F=2.74, d f=9 / 252, p<.01)$ resulted from faster acquisition for all groups in the second replication.

The considerable drop in running speeds for all groups across extinction led to a significant day effect $(F=32$, $\mathrm{df}=9 / 252, \quad p<.001)$. The increased resistance to extinction of IM groups over both replications led to a significant Group by Day interaction $(\mathrm{F}=1.63$, df $=$ $27 / 252, p=.02$ ) in the run measure. In the run, goal, and total measures, the Replication by Group by Day interactions were all significant $(F s=2.86,2.46,2.09$, $\mathrm{df}=27 / 252$, ps $<.01$ in all cases). Because of the triple interaction, separate analyses over all 10 days of 
Fig. 2. Group by day total speed means for acquisition and extinction.

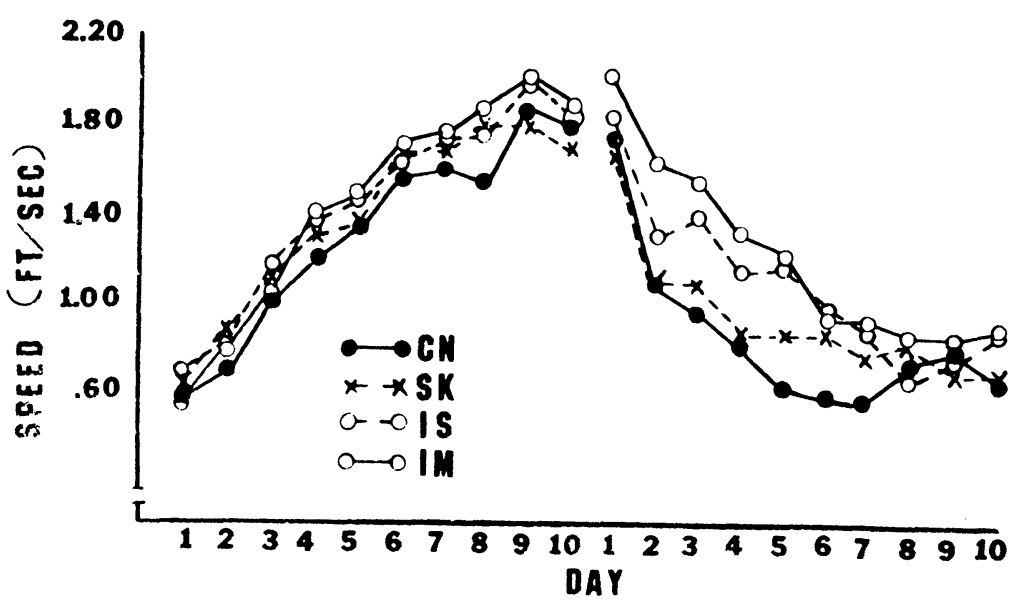

Thus, the Replication by Group by Day interaction which was significant in three of the four measures in the overall analysis is due primarily to the persistence displayed by IS, SK, and IM groups relative to control groups across replications.

The increased resistance to extinction of IM, IS, and SK Ss in Replication 1 and of IM Ss in Replication 2 relative to the controls lends partial support to the earlier findings (Amsel et al, 1971). However, the persistence of these groups was strong enough across both replications to be significant only in the run measure of the overall analysis.

Approach data from the imprinting phase of the experiment suggests at least a partial explanation for the different pattern of results across replications. There were substantial differences in the strength of approach to the shock-obstructed imprinting stimulus across replications and there is evidence for a relationship between strength of shock-obstructed approach to the imprinting stimulus and subsequent persistence. The imprinting/shock Ss in Replication 1 displayed greater approach to the imprinting stimulus than the IS Ss in Replication 2, and they were also persistent. The relationship between strength of approach to the stimulus and subsequent persistence also appears in IS Ss even within the second replication.

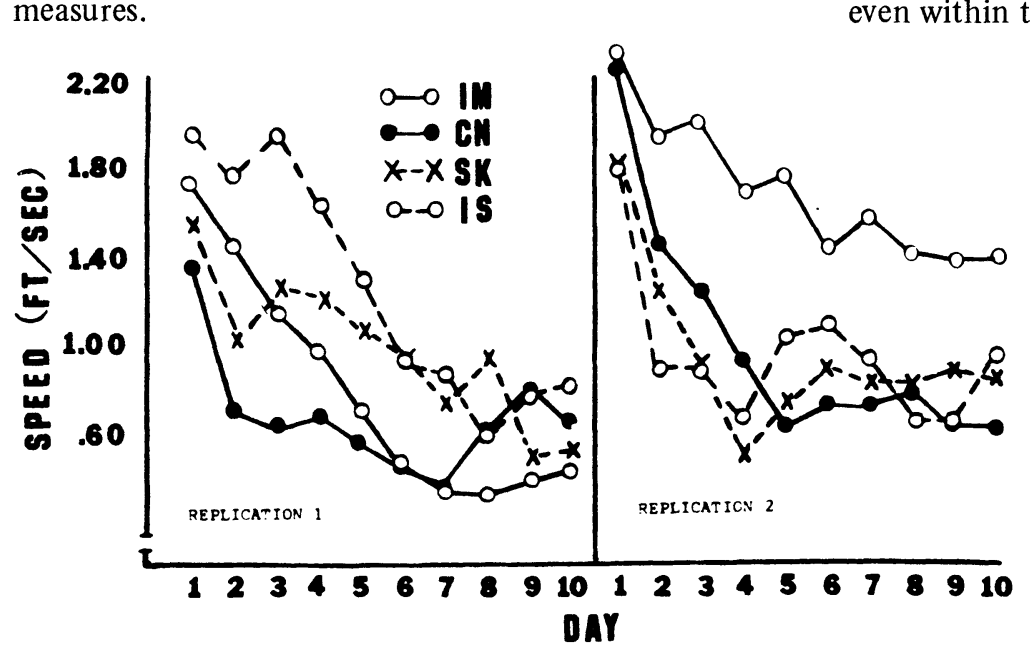

Fig. 3. Group by day total extinction speeds for Replications 1 and 2 . 
The average distance approached on imprinting trials for Ss in Group IS in Replication 2 was .58, .25, .25, 1.42, and $1.58 \mathrm{ft}$. The corresponding average total extinction running speeds in $\mathrm{ft} / \mathrm{sec}$ were $.30,56, .91,1.34$, and 1.69. The average total extinction speed for the corresponding yoked shock controls were $.62, .47, .55$, 1.95 , and 1.08. Ss 4 and 5 in Group IS were the best stimulus approachers and maintained the fastest running speeds in extinction, as did Ss 4 and 5 in Group SK, which were their yoked shock controls.

According to a general theory of persistence (Amsel, 1971), persistence may result not only from counterconditioning to approach but also from habituation processes which may in themselves involve a type of counterconditioning. In the present experiment, those Ss most likely to be counterconditioned to approach or to habituate to shock were those IS Ss which consistently approached the obstructed imprinting stimulus and their yoked shock controls. The data provide some support for such an analysis. The imprinting/shock Ss which showed the most consistent approach to the imprinting stimulus also showed the highest average running speeds in extinction. Similarly, their yoked shock controls, which received the greatest amount of shock among the shock control Ss, were the most persistent Ss in that group. A comparison of the two replications in Fig. 3 may reflect that the greater average approach of shock control Ss in Replication 1 (.20 ft vs .05 ft in Replication 2) was what led to their greater persistence in Replication 1 as compared to Replication 2.

However, differences in imprinting, unobstructed by shock, cannot be used to explain the subsequent differential persistence of IM Ss across replications. Though the IM Ss were more presistent in Replication 2, average imprinting approach distance per trial was less in the second replication (1.78 vs $2.25 \mathrm{ft})$. Thus, it remains to be explained why some instances of unobstructed imprinting and not others result in increased persistence.

It is also interesting to note that in both the earlier experiment (Amsel et al, 1971) and in the present experiment, the shock control groups were more persistent than the handled controls. Such a finding lends generality to the finding of Wong (1971) that rats subjected to free shocks are more resistant to sugsequent runway extinction.

Taken together, the results of Amsel et al (1971) and of the present experiment support the conclusion that in young domestic chicks, shock, either as an obstruction to imprinting or administred independently of behavior, may lead to relative persistence in runway extinction. The conditions under which unobstructed imprinting approach leads to increased persistence are less clear.

\section{REFERENCES}

Amsel, A. Behavioral habituation, counterconditioning, and a general theory of persistence. In A. H. Black and W. F. Prokasy (Eds.), Classical conditioning II: Current research and theory. New York: Appleton-Century-Crofts, 1972.

Amsel, A., Glazer, H., Lakey, J. R., McCuller, T., \& Wong, P. T. $P$. Introduction of acoustic stimulation during acquisition and resistance to extinction in the normal and hippocampal damaged rat. Journal of Comparative \& Physiological Psychology, 1973, 84, 176-186.

Amsel, A., Wong, P. T. P., \& Scull, J. Transfer of persistence in the domestic chick: Imprinting, punishment and resistance to extinction of a food-reward running response. Psychonomic Science, 1971, 25, 174-176.

Brown, R. T. \& Wagner, A. R. Resistance to punishment and extinction following training with shock on nonreinforcement. Journal of Experimental Psychology, 1964, 68, 503-507.

Donin, J. A., Surridge, C. T., \& Amsel, A. Extinction following partial delay of reward with immediate continuous reward interpolated at 24-hour intertrial intervals. Journal of Experimental Psychology, 1967, 74, 50-53.

Wong, P. T. P. Coerced approach to shock and resistance to punishment suppression and extinction in the rat. Journal of Comparative \& Physiological Psychology, 1971, 75, 82-89.

(R eceived for publication July 8, 1974.) 